\title{
NON SURGICAL TREATMENT OF CHRONIC PERIODONTITIS BY TWO STRATEGIES OF FULL MOUTH DISINFECTION
}

\author{
Ahmed Mortada Fikry Abdel Hamed
}

\begin{abstract}
Introduction: Recent studies reported additional clinical improvement when moderate chronic periodontitis was treated by means of a one stage full mouth disinfection instead of standard treatment .The one stage full mouth disinfection procedure involves periodontal debridement of all pockets within 24 hours with application of an irrigation to all intraoral niches such as periodontal pockets and tongue dorsum.
\end{abstract}

Aim : The aim of this randomized clinical trial was to assess the clinical improvement of chronic moderate periodontitis after full mouth disinfection compared to periodontal debridement alone .

Subjects and methods: Thirty patients ( 18 males and 12 females ) suffering from moderate chronic periodontitis, free from any systemic disorders were recruited from the outpatient clinic, Faculty of Dentistry - Assiut University and presented at the department of Periodontology for assessment and treatment. Patients were assigned to the following groups:

Group I: patients received scaling and root planing. Group II: patients received a full mouth disinfection including a full mouth scaling and root planing in combination with a disinfection of all intraoral niches by means of chlorhexidine. Group III: patients received a full mouth disinfection including a full mouth scaling and root planing in combination with a disinfection of all intraoral niches by means of tetracycline. Randomization of the patients and blinding of assessment were performed to avoid bias. Statistical analysis was performed with IBM SPSS statistics version 20 for windows.

Results: Pocket reduction mean of group I was $(+-1.8 \mathrm{~mm})$, gain of attachment mean for group I was $(+-2.7 \mathrm{~mm})$, Pocket reduction mean of group II was $(+-1.2 \mathrm{~mm})$, gain of attachment mean for group II was $(+-2.5 \mathrm{~mm})$, Pocket reduction mean of group III was $(+-1.1 \mathrm{~mm})$, gain of attachment mean for group III was $(+-2.3 \mathrm{~mm})$

Conclusion : All three treatment modalities showed clinical improvement. Full mouth disinfection either by chlorhexidine or tetracycline gave better clinical results than regular periodontal debridement but there were no statistically significant differences.

* BDS- MSc - PhD, Lecturer of Periodontology - Assiut University 


\section{INTRODUCTION}

Chronic periodontitis is an inflammatory disease of the gingiva, bone and periodontal ligament of a bacterial origin and can eventually lead to tooth loss. (1) Bacteria which exist in the subgingival plaque mainly are the main cause of the periodontal diseases.(2) Bacteria colonize at the tooth surfaces as biofilm, which consists of gram-positive, gramnegative, aerobic, facultative, and anaerobic microorganisms which deposit sequentially. ${ }^{(3)}$

Periodontal debridement is usually performed over three months divided into quadrants with one week interval between the dental visits. ${ }^{(4)}$ The drawback of this way of debridement is fast recolonization of the bacteria and transmission from un treated sites to the treated sites. ${ }^{(5)}$

Consequently, full mouth disinfection was suggested to avoid this problem this includes periodontal debridement, tongue scrubbing and irrigation of periodontal pockets within 24 hours. ${ }^{(6)}$ Recent modification of the full mouth disinfection includs adding of azithromycin antibiotics ${ }^{(7)}$, or povidone iodine and the use of ultrasonic instrumentation. ${ }^{(8)}$

\section{AIM OF THE STUDY}

This study was a randomized clinical trials to evaluate the relative importance of tetracycline as an irrigation of the pockets in the one stage full mouth disinfection in comparison with the full mouth disinfection with the use of chlorhexidine, in contrast to the regular periodontal debridement by scaling and root planing only in the treatment of chronic moderate periodontitis.

\section{SUBJECTS AND METHODS}

Thirty patients ranging in age from 30 to 60 years (18 males and 12 females) recruited from the out patient clinic of Facukty of Dentistry Assiut University and presented at the Department of Periodontology for assessment and treatment of chronic periodontitis.

\section{Inclusion criteria :}

All patients were free from any systemic disease. Each patient had at least 2 multirooted teeth and at least 2 single rooted teeth, with at least 3 sites having a probing depth of $>5 \mathrm{~mm}$, Clinical attachment loss 3-4 mm which and bleeding on probing and with radiographic evidence of bone loss.

\section{Patients were randomly assigned to three groups}

Group I: patients treated by only scaling by hand, ultrasonic instruments and root planing by hand instruments divided in quadrants within one week, figure (1).

Group II: patients treated by Full-mouth scaling and root planing (the entire dentition in two visits within 24 h, i.e. two consecutive days). Subgingival irrigation (three times, repeated within $10 \mathrm{~min}$.) of all pockets with a $1 \%$ chlorhexidine gel in order to suppress the remaining bacteria. Tongue brushing by the patient with a $1 \%$ chlorhexidine gel for 1 min. Chairside mouth rinsing by the patient with a $0.2 \%$ chlorhexidine solution for $2 \mathrm{~min}$. and in the pharynx, including the tonsils (by gargling or via the use of a local spray), prior to and after each session of root planing. Optimal oral hygiene, supported during the first 2 months by a $0.2 \%$ chlorhexidine mouthrinse to retard the recolonization of the pockets., figure (2)

Group III : Patients treated with full-mouth scaling and root planing and tongue scrubbing ( two visits within 24 hours). An additional subgingival irrigation (three times, repeated within $10 \mathrm{~min}$.) of all pockets with $1 \mathrm{~mL}$ of TTC-HCL (Tetracid ${ }^{\circledR} 500$ mg.) at a concentration of $50 \mathrm{mg} / \mathrm{mL}$. TTC-HCL was deposited into the periodontal pocket slowly (30 s) using a syringe $(1 \mathrm{~mL})$ and an insulin needle. TTC-HCL solutions were prepared by dissolving the content of $500 \mathrm{mg}$ TTC-HCL capsules into 10 $\mathrm{mL}$ distilled sterile water. :,figure (3) 


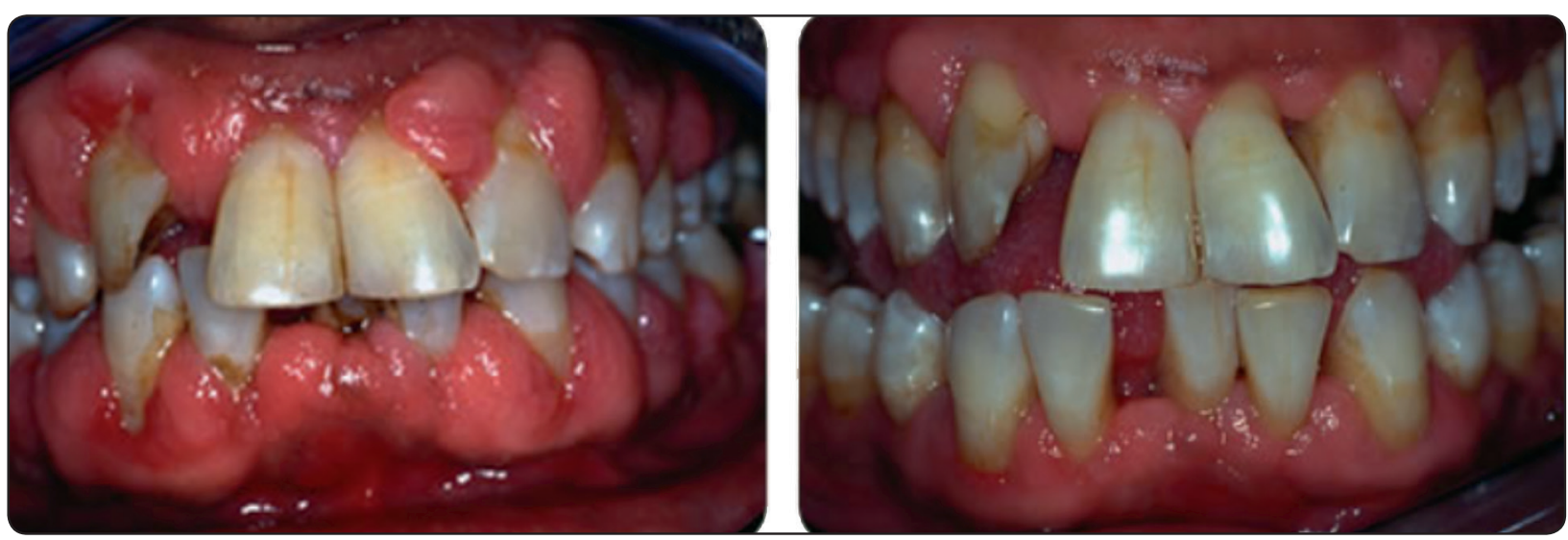

Fig. (1) : Showing before and after debridement for group one.

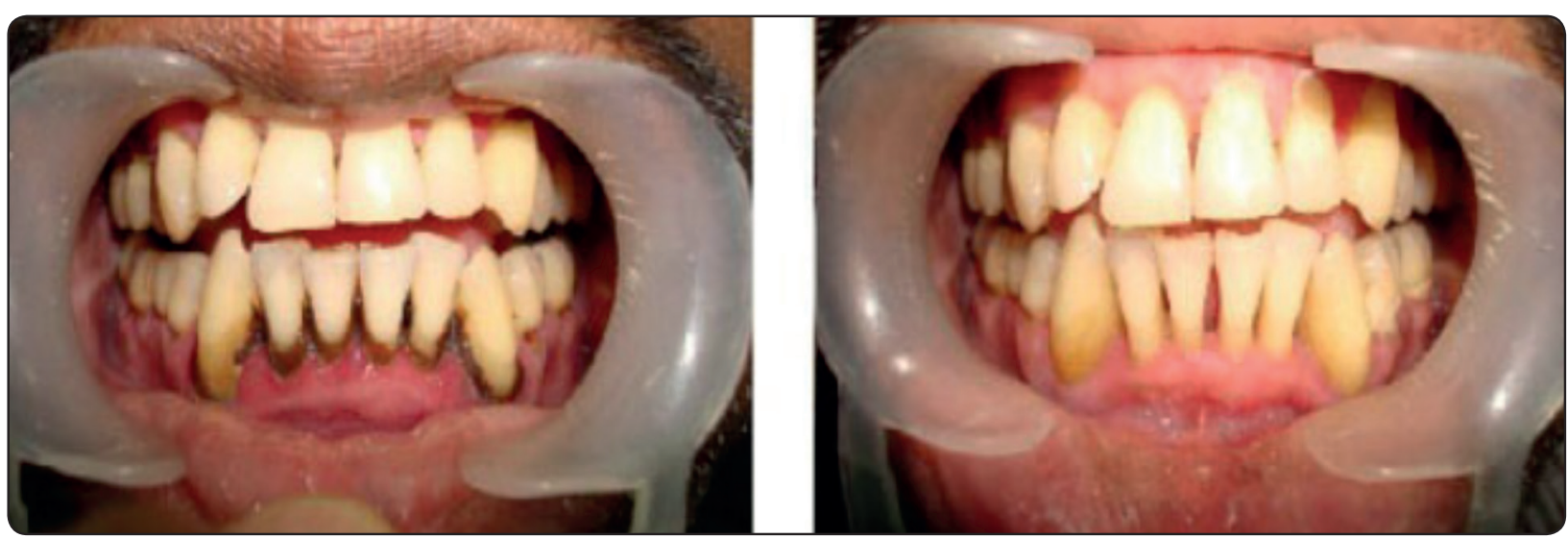

Fig. (2) : Showing before and after full mouth disinfection for group two.

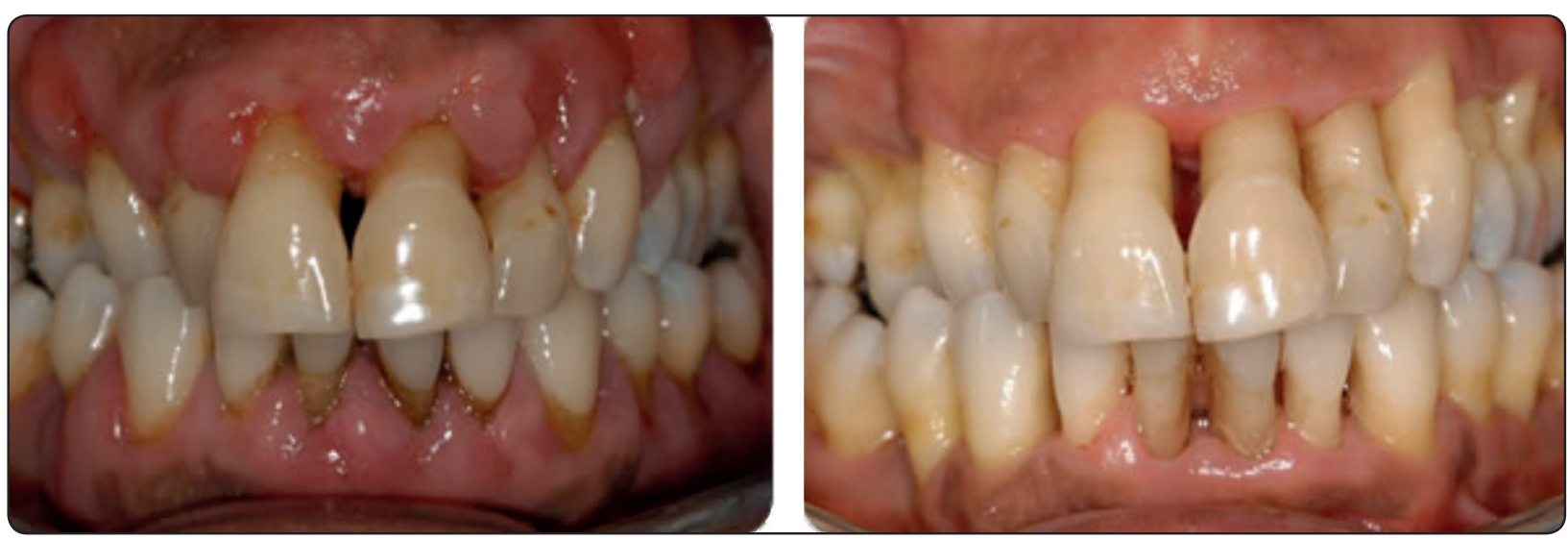

Fig. (3) : Showing before and after treatment for group three.. 
Periodontal debridement for all groups started without any local anesthesia unless the patients felt pain in deeper sites debridement.

Clinical parameters included probing depth, clinical attachment loss and bleeding on probing taken prior to treatment, 3 months for reevaluation and 6 months as follow up.

All patients received standard oral hygiene instructions. These instructions included interdental plaque control (tooth picks and/or interdental brushes) and tooth and tongue (dorsum) brushing twice daily.

\section{RESULTS}

Pocket reduction mean of group I was (+$1.8 \mathrm{~mm}$ ), gain of attachment mean for group I was (+-2.7mm), Pocket reduction mean of group II was $(+-1.2 \mathrm{~mm})$, gain of attachment mean for group II was $(+-2.5 \mathrm{~mm})$, Pocket reduction mean of group III was $(+-1.1 \mathrm{~mm})$, gain of attachment mean for group III was $(+-2.3 \mathrm{~mm})$.

\section{Statistical Analysis}

Numerical data were explored for normality by checking the distribution of data and using tests of normality (Kolmogorov-Smirnov and Shapiro-Wilk tests).

Qualitative data were presented as frequencies and percentages. Chi-square test was used for comparisons regarding qualitative data.

For parametric data; one way ANOVA test and Paired-Samples $\mathrm{T}$ test were used to compare between in the three groups. For non-parametric data; Wilcoxon test was used to compare between each two groups.

The significance level was set at $\mathrm{P} \leq 0.05$. Statistical analysis was performed with IBM SPSS Statistics Version 20 for Windows.

\section{Demographic data}

There was no statistically significant difference between mean age values in the three groups. There was also no statistically significant difference between gender distributions in the three groups.

TABLE (1): Descriptive statistics and results of comparison between demographic data in the three groups

\begin{tabular}{|c|c|c|c|c|}
\hline \multirow[t]{2}{*}{ Demographics } & Group I & Group II & $\begin{array}{c}\text { Group } \\
\text { III }\end{array}$ & \multirow[t]{2}{*}{$P$-value } \\
\hline & $(\mathbf{n}=10)$ & $(\mathbf{n}=10)$ & $(\mathbf{n}=10)$ & \\
\hline \multicolumn{5}{|l|}{ Age } \\
\hline Mean \pm SD & $\begin{array}{c}44.9 \pm \\
11.77\end{array}$ & $\begin{array}{c}46.5 \pm \\
8.68\end{array}$ & $\begin{array}{c}39.9 \pm \\
9.17\end{array}$ & 0.319 \\
\hline \multicolumn{5}{|c|}{ Gender $[\mathrm{n},(\%)]$} \\
\hline Male & $\begin{array}{c}6 / 10 \\
(60 \%) \\
\end{array}$ & $\begin{array}{c}5 / 10 \\
(50 \%) \\
\end{array}$ & $\begin{array}{c}7 / 10 \\
(70 \%) \\
\end{array}$ & \multirow{2}{*}{0.659} \\
\hline Female & $\begin{array}{c}4 / 10 \\
(40 \%) \\
\end{array}$ & $\begin{array}{c}5 / 10 \\
(50 \%) \\
\end{array}$ & $\begin{array}{c}3 / 10 \\
(30 \%) \\
\end{array}$ & \\
\hline
\end{tabular}

*: Significant at $P \leq 0.05$

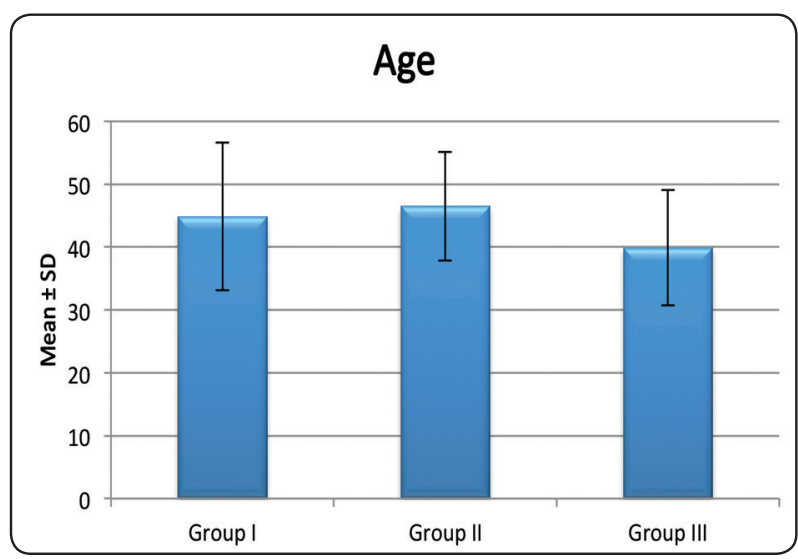

Fig. (4): Column chart representing distribution of age in the three groups

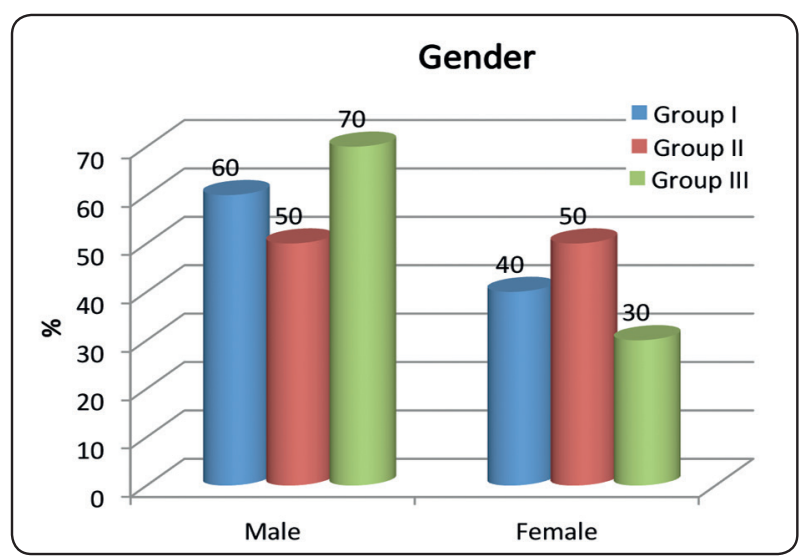

Fig. (5): Cylinder chart representing distribution of gender in the three groups 


\section{Pocket depth mean}

There was statistically significant difference $(<0.005)$ between Pre-operative and Post-operative of Pocket depth mean in the three groups.

TABLE (2): Descriptive statistics and results of Wilcoxon test for comparison between each two groups

\begin{tabular}{lccc}
\hline $\begin{array}{l}\text { Pocket } \\
\text { depth mean }\end{array}$ & $\begin{array}{c}\text { Group I } \\
(\mathbf{n}=\mathbf{1 0})\end{array}$ & $\begin{array}{c}\text { Group II } \\
(\mathbf{n}=\mathbf{1 0})\end{array}$ & $\begin{array}{c}\text { Group III } \\
(\mathbf{n}=\mathbf{1 0})\end{array}$ \\
$\begin{array}{lccc}\text { Pre-operative } \\
\text { Mean } \pm \text { SD }\end{array}$ & $3.3 \pm 2.26$ & $3.7 \pm 0.13$ & $3.6 \pm 0.105$ \\
Median (IQ) & 2.5 & 3.7 & 3.6 \\
$(2.09-3.27)$ & $(3.6-3.8)$ & $(3.58-3.63)$ \\
Post-operative & & & \\
Mean \pm SD & $1.8 \pm 1.16$ & $1.2 \pm 0.067$ & $1.1 \pm 0.067$ \\
Median (IQ) & 1.55 & 1.2 & 1.1 \\
\hline P-value & $0.004 * *$ & $0.000^{* *}$ & $0.000^{* *}$ \\
\hline
\end{tabular}

*: Significant at $P \leq 0.05$

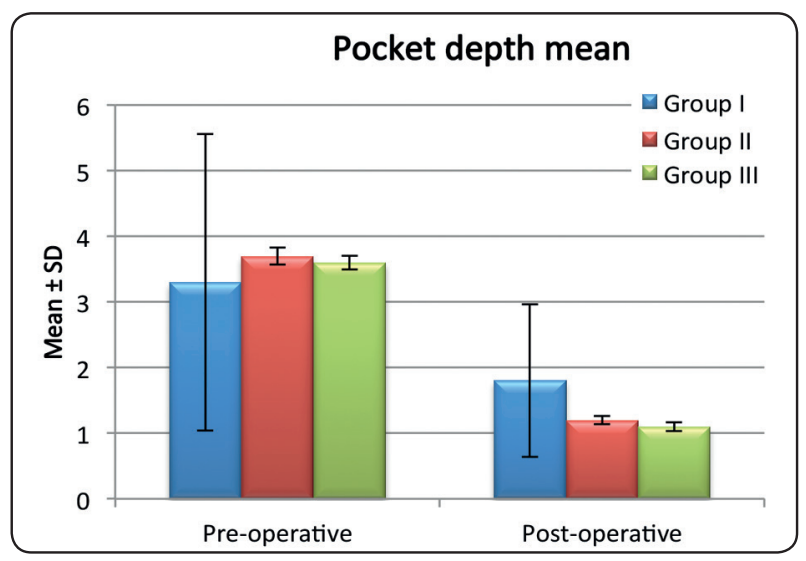

Fig. (6): Column chart representing comparison between Preoperative \& Post-operative pocket depth mean in the studied groups

\section{CAL mean}

There was statistically significant difference $(<0.005)$ between pre-operative and post-operative CAL mean in the three groups.
Table (3): Descriptive statistics and results of Wilcoxon test for comparison between each two groups

\begin{tabular}{|c|c|c|c|}
\hline CAL mean & $\begin{array}{l}\text { Group I } \\
(n=10)\end{array}$ & $\begin{array}{l}\text { Group II } \\
(\mathbf{n}=\mathbf{1 0})\end{array}$ & $\begin{array}{l}\text { Group III } \\
(\mathbf{n}=\mathbf{1 0})\end{array}$ \\
\hline \multicolumn{4}{|c|}{ Pre-operative } \\
\hline Mean $\pm \mathrm{SD}$ & $4.3 \pm 4.57$ & $4.2 \pm 0.17$ & $4.5 \pm 0.16$ \\
\hline $\begin{array}{l}\text { Median } \\
\text { (IQ) }\end{array}$ & $\begin{array}{c}2.6 \\
(2.1-4.33)\end{array}$ & $\begin{array}{c}4.15 \\
(4.08-4.33)\end{array}$ & $\begin{array}{c}4.5 \\
(4.38-4.55)\end{array}$ \\
\hline \multicolumn{4}{|c|}{ Post-operative } \\
\hline Mean \pm SD & $2.7 \pm 3.27$ & $2.5 \pm 0.094$ & $2.3 \pm 0.16$ \\
\hline $\begin{array}{l}\text { Median } \\
\text { (IQ) }\end{array}$ & $\begin{array}{c}1.7 \\
(1.5-1.83) \\
\end{array}$ & $\begin{array}{c}2.5 \\
(2.4-2.53) \\
\end{array}$ & $\begin{array}{c}2.25 \\
(2.2-2.33)\end{array}$ \\
\hline P-value & $0.010 *$ & $0.000^{* *}$ & $0.000 * *$ \\
\hline
\end{tabular}

*: Significant at $P \leq 0.05$

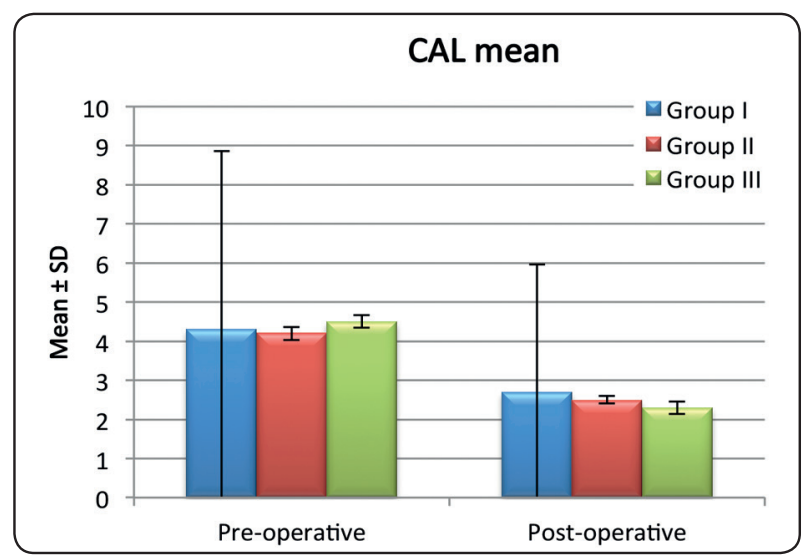

Fig. (6): Column chart representing comparison between Preoperative \& Post-operative pocket depth mean in the studied groups

\section{DISCUSSION}

Full-mouth disinfection was proposed by Quirynen et al. in (1995), to remove bacteria in the pockets, tongue, tonsils and oropharynx within 24 hours to avoid any cross infection from untreated sites to the treated ones. Many studies had mentioned the benefits of full mouth disinfection from the clinical and microbial point of view. ${ }^{(6,9)}$ 
In the present study, full mouth disinfection with the use of chlorhexidine as an irrigation to the pockets and in disinfection of the tongue and tonsils in group II showed pocket depth reduction, gain of attachment and clinical resolution of moderate periodontitis ; The improvement could be due to the use of irrigation that reduced the supragingival bacteria which could thus reduce the gingival inflammation ${ }^{(10)}$. The second explanation could be the interference with plaque maturation and improvement of host response by detaching the subgingival bacteria ${ }^{(11)}$. The third explanation could be reducing the thickness of biofilm due to substantivity of chlorhexdine action which mean the prevention of adherence of material to the defective root surface over an extended time period. ${ }^{(12)}$ The forth explanation could be the avoidance of cross contamination from the untreated sited to treated ones because of on stage full mouth disinfection effect. ${ }^{(9)}$

In this study, Group III (tetracycline irrigation) showed great resolution of the disease in terms of pocket reduction and clinical attachment gain after 6 months after use of full mouth disinfection concept and use of the tetracycline HCL which could be attributed to removal of bacterial plaque from the pockets by mechanical debridement and the antibacterial effect of tetracycline. ${ }^{(8)}$

The local use of tetracycline HCLas a subgingival irrigation avoids the complications of the systemic use of tetracycline with more concentration at the diseased sites. The critical concentration of the local use at the pockets was more than $1 \mathrm{mg} / \mathrm{ml}$. which makes the drug bactericidal to most of the bacteria which could resist the systemic approach. ${ }^{(13)}$

Non surgical debridement by divided visits has shown pocket reduction and gain of the clinical attachment; which could be attributed to mechanical removal of the causative bacterial factors, also there was no statistical differences between the control group and the comparative two groups using the full mouth disinfection . It is advised when using the several visits debridement to perform complete bacterial removal in the same segment either supra or subgingivally ; because after supra ginvgival debridement only gingival shrinkage due to inflammation resolution could close the pocket orifice overlying subgivival bacterial complicated by periodontal abscess formation..$^{(14,15)}$

\section{CONCLUSIONS}

The three modalities of chronic moderate periodontitis treatment have shown clinical improvement, pocket depth reduction and clinical attachment gain. Full mouth disinfection protocols either by tetracycline or chlorohexidine maybe considered more effective clinically than the regular periodontal debridement although there were no statistically significant differences.

The author declares no conflict of interests.

\section{REFERENCES}

1- Cekici A, Kantarci A, Hasturk H, and Van Dyke TE, Inflammatory and immune pathways in the pathogenesis of periodontal disease, Periodontol 2000. 2014 Feb; 64(1): 57-80.

2- Nishihara T \& Koseki T, Microbial etiology of Periodontitis, Periodontology 2000, Vol. 36, 2004, 14-26.

3- Davies RM, Børglum Jensen S, Rindom Schiøtt C \& Löe $\mathrm{H}$, The effect of topical application of chlorhexidine on the bacterial colonization of the teeth and gingiva, journal of periodontal research, April 1970,Volume5, Issue2, Pages 96-101

4- Badersten, A., Nilve 'us, R. \& Egelberg, J. (1981) Effect of nonsurgical periodontal therapy. I. Moderately advanced periodontitis. Journal of Clinical Periodontology 8, 57-72.

5- Van der Velden, U., Van Winkelhoff, A. J., Abbas, F. \& De Graaff, J. (1986) The habitat of periodontopathic microorganisms. Jour- nal of Clinical Periodontology 13, 243 248 .

6- Quirynen, M., Bollen, C. M., Vandekerckhove, B. N., Dekeyser, C., Papaioannou, W. \& Eyssen, H. (1995) Full- vs. 
partial-mouth disinfection in the treatment of periodontal infections. Short-term clinical and microbio- logical observations. Journal of Dental Research 74, 1459-1467.

7- Gomi, K., Yashima, A., Nagano, T., Kanazashi, M., Maeda, N. \& Arai, T. (2007) Effects of full-mouth scaling and root planing in con- junction with systemically administered azi- thromycin. Journal of Periodontology 78, 422-429.

8- Zanatta, G. M., Bittencourt, S., Nociti Jr., F. H., Sallum, E. A., Sallum, A. W. \& Casati, M. Z. (2006) Periodontal debridement with povidone-iodine in periodontal treatment: short-term clinical and biochemical observations. Journal of Periodontology 77, 498- 505.

9- Kinane DF, Papageorgakopoulos G. Full mouth disinfection versus quadrant debridement: the clinician's choice, J Int Acad Periodontol. 2008 Jan; 10(1):6-9.

10- Quirynen M, De Soete M, Boschmans G, Pauwels M , Coucke W, Teughels W \& Van Steenberghe D, Benefit of "one-stage full-mouth disinfection" is explained by disinfection and root planing within 24 hours: a randomized controlled trial, Journal of Clinical Periodontology, Volume33, Issue9, September 2006, Pages 639-647.

11- Quirynen M, Mongardini C, de Soete M, Pauwels M, Coucke W, van Eldere J\& van Steenberghe D.,The rôle of chlorhexidine in the one-stage full-mouth disinfection treatment of patients with advanced adult periodontitis. Long-term clinical and microbiological observations, J Clin Periodontol. 2000 Aug;27(8):578-89.

12- Marcela R. Carrilho, Ricardo M. Carvalho, Ethan N. Sousa, José Nicolau, Lorenzo Breschi, Annalisa Mazzoni, Leo Tjäderhane, Franklin R. Tay, Kelli Agee \& David H. Pashley,Substantivity of Chlorhexidine to Human Dentin, Dent Mater. 2010 Aug; 26(8): 779-785.

13- Dodwad V, Ahuja S \& Jha Kukreja B, Effect of locally delivered tetracycline hydrochloride as an adjunct to scaling and root planing on Hbalc, C-reactive protein, and lipid profile in type 2 diabetes: A clinico-biochemical study, Contemp Clin Dent. 2012 Apr-Jun; 3(2): 150-154.

14- Latheef P, Sirajuddin S, Gundapaneni V, Kumuda MN, and Ashwini A,Iatrogenic Damage to the Periodontium Caused by Periodontal Treatment Procedures, Open Dent J. 2015; 9: 203-207.

15- Hans R, Gjermo P \& Baelum V, A double-masked Randomized Clinical Trial (RCT) comparing four periodontitis treatment strategies: 5-year clinical results, Clinincal Periodontology, 2017 Volume 44, Issue 10 . 